Discussion

Papers

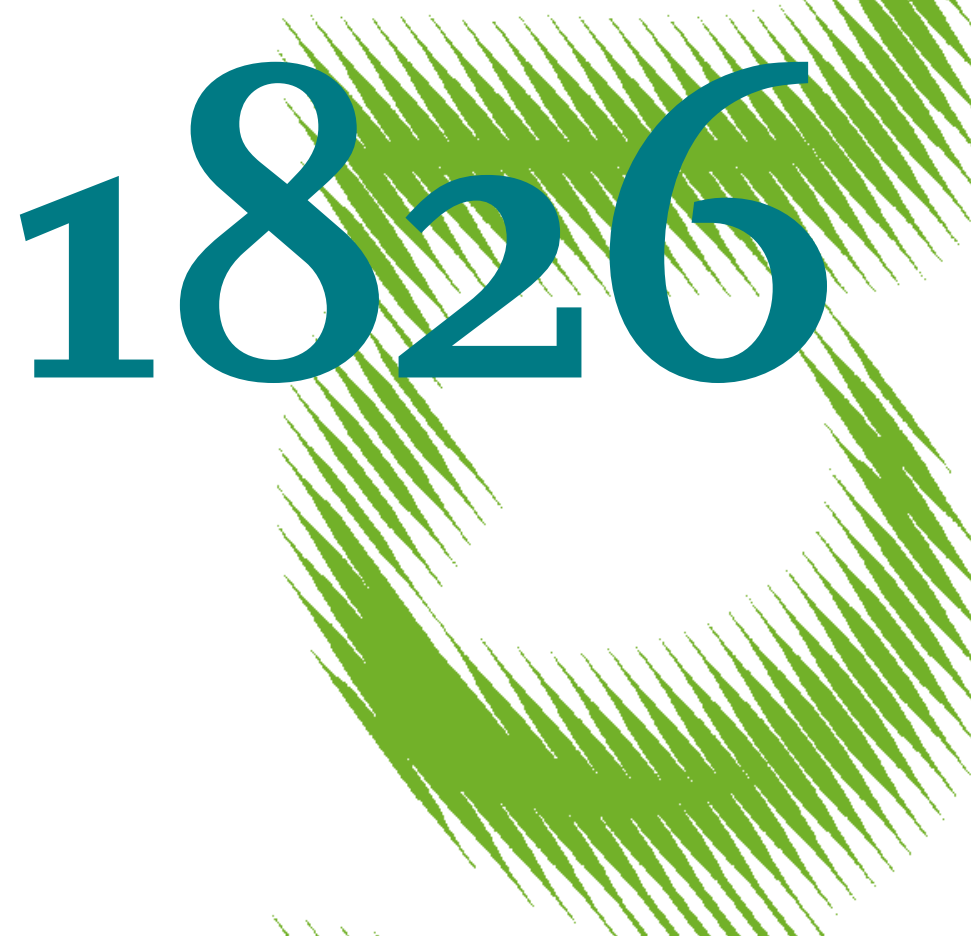

Cheating and Corruption: Evidence from a Household Survey 
Opinions expressed in this paper are those of the author(s) and do not necessarily reflect views of the institute.

IMPRESSUM

(C) DIW Berlin, 2019

DIW Berlin

German Institute for Economic Research

Mohrenstr. 58

10117 Berlin

Tel. +49 (30) $89789-0$

Fax +49 (30) $89789-200$

http://www.diw.de

ISSN electronic edition 1619-4535

Papers can be downloaded free of charge from the DIW Berlin website:

http://www.diw.de/discussionpapers

Discussion Papers of DIW Berlin are indexed in RePEc and SSRN:

http://ideas.repec.org/s/diw/diwwpp.html

http://www.ssrn.com/link/DIW-Berlin-German-Inst-Econ-Res.html 


\title{
Cheating and Corruption: Evidence from a Household Survey*
}

\author{
Olaf Hübler ${ }^{\dagger} \quad$ Melanie Koch ${ }^{\ddagger} \quad$ Lukas Menkhoff ${ }^{\S}$ Ulrich Schmidt
}

October 2019

\begin{abstract}
This study tests the prediction that a corrupt government reduces ethical behavior among its citizens. We integrate a standard "cheating" experiment into a broad household survey and find clear support for this prediction: respondents who perceive corruption in state affairs are more likely to cheat. Interestingly, there is a small group of non-conformers. The main relation is robust to consideration of many (largely insignificant) socio-demographic control variables. Attendance of others at the cheating experiment, thus stimulating the reputational concern to be seen as honest, reduces cheating. Again, this does not diminish the predictive role of corruption.
\end{abstract}

Keywords: Cheating; Corruption; Individual Characteristics; Lab-in-the-Field Experiment

JEL: D81 (decision-making under risk); D91 (.. psychological, social factors on decision making); D73 (...; corruption)

This paper has been updated. The current version is published as DIW Discussion Paper 1917

*We thank participants at several seminars as well as Johannes Abeler, Eugen Dimant, Antonia Grohmann, and Menusch Khadjavi for helpful comments. Declarations of interest: none. Financial support by the German Research Foundation (DFG grant ME 1070/8) is gratefully acknowledged.

${ }^{\dagger}$ Leibniz University Hannover, Königsworther Platz 1, D-30167 Hannover, Germany; huebler@ewifo.uni-hannover.de.

${ }^{\ddagger}$ Humboldt-University Berlin, and German Institute for Economic Research (DIW Berlin), D-10108 Berlin, Germany; Melanie.Koch@diw.de.

${ }^{\S}$ Humboldt-University Berlin, and German Institute for Economic Research (DIW Berlin), D-10108 Berlin, Germany; lmenkhoff@diw.de.

`Kiel Institute for the World Economy, Kiellinie 66, D-24105 Kiel, University of Johannesburg and University of Kiel, Germany; Ulrich.Schmidt@ifw-kiel.de. 


\section{Introduction}

Economic theory predicts that individuals cheat if it increases their payoff, especially if cheating cannot be detected. Several experiments and studies confirm this prediction, including the well-established experiment of Fischbacher and Föllmi-Heusi (2013). While people tend to cheat, by far not all people do so. On average, they forgo about threequarters of the maximum payoff they could earn, as the meta-study by Abeler et al. (2019) reveals. Obviously, although the norm of honesty is strong, it is frequently violated. What circumstances might contribute to discarding honesty and, in particular, does the violation of other related norms in society, such as corruption, play a role?

It is well documented that corruption detrimentally affects how society functions (for a comprehensive overview see Dimant and Tosato, 2018). Among others, it is argued that corruption contributes to a general decline of ethical behavior (e.g. Aidt, 2003; Lambsdorff, 2007). The supposed mechanism is that people experience corrupt practices (either personally or through others), in particular by officials. This, subsequently, undermines their belief in norms in general and provides a bad example of taking personal advantage over obeying societal norms. While the link between individually perceived corruption and cheating seems plausible, we are the first - to our knowledge - to directly examining this relationship in a larger household sample.

Accordingly, we integrate a standard cheating experiment, following Fischbacher and Föllmi-Heusi (2013), into a household survey with more than 500 participants in Thailand. Embedding the experiment in a household survey ensures that we can link cheating to extensive individual and household information. Additionally, Thailand is plagued by a high level of corruption (however, still at a conventional level for emerging economies such as Brazil or China, see World Bank Worldwide Governance Indicators (2018)), which makes it an interesting study site.

We find that cheating and the perception of prevalent corruption are positively related, suggesting that perceived corruption in state affairs influences individual cheating. This holds for the overwhelming majority (more than $93 \%$ ), which we analyze in more detail, while a small group responds honestly despite perceiving a high degree of corruption. In all cases, corruption is the exogenous driver as it is based on the observation of society while cheating is an individual decision, which makes reverse causality unlikely. Moreover, motivated beliefs (e.g., to avoid cognitive dissonance) or wishful thinking can largely be excluded because perceived corruption is elicited a year before the cheating experiment takes place.

In order to control the relationship between corruption and cheating for potentially confounding factors, we consider a larger set of individual and situational characteristics. We find that socio-demographic characteristics are rather unrelated to cheating; this is 
in line with the results of Abeler et al. (2019). In our sample, older participants tend to cheat less, but only up to an age of about 50 years; thereafter, cheating increases. Furthermore, a higher risk tolerance is, in some empirical specifications, related to more cheating. However, other characteristics, among them being male, remain unrelated to cheating.

According to Abeler et al. (2019), two kinds of underlying preferences are necessary to explain the observed behavior of a limited degree of cheating theoretically. The few individual characteristics mentioned above can be related to a preference for being honest. The second underlying preference is an individual's preference for an honest reputation. Reputation seems to be at stake if other persons observe the outcome of the experiment and, thus, an element of suspicion of cheating is induced (Kajackaite and Gneezy, 2017). We directly test this implication of "reputational concerns" by allowing others to be present when starting the household survey; the experiment is conducted at a later stage of the questionnaire. Thus, attendance is decided before the experiment (whose content is unknown to the participants ex ante and, therefore, largely exogenous. We confirm the theoretically expected negative relationship, i.e. if there are attendants, the degree of cheating is reduced. Hence, we do not just identify a few specific characteristics related to cheating, but also, in line with the finding of Abeler et al. (2019), that two kinds of preferences explain cheating behavior.

In modeling the relation between cheating and corruption, we first separate the aforementioned small group that responds honestly despite perceiving high corruption. Second, we show that relations of interest are revealed more precisely if a regression model with weights is used, where groups of respondents with a higher probability of cheating receive clearly lower weights. The reason is that these groups consist of cheaters and non-cheaters, which makes the summary information difficult to allocate to either subgroup. In contrast, the information of a group with hardly any cheaters clearly belongs to non-cheaters. When we moderate this weighting, either by using sampling weights for all groups of respondents, or by using an interval regression or an ordered logit model, coefficients point in the same direction and keep their relative importance, but the standard errors are higher, turning many coefficients insignificant. Thus, employing a weighted regression model may be particularly helpful for samples that are relatively small or noisy.

While these findings on cheating are new to the literature - to the best of our knowledge - it is crucial that they are based on a conventional sample. Our experiment is set in a relatively poor area in rural Thailand, meaning that - given the comparatively high stakes of our experiment - the opportunity cost of honesty (i.e. not cheating) are high. However, it is reassuring that our sample, by and large, reproduces five stylized facts as documented by Abeler et al. (2019): (i) individuals do cheat; (ii) individuals do not only 
cheat by choosing the maximum outcome; (iii) it follows that the degree of cheating is $30 \%$ and, hence, much below the maximum (100\%), which is in line with the average of $25 \%$ found in the literature; (iv) men cheat more than women (although not to a significant degree in our sample); and (v) age is non-linearly related to cheating; there is a negative relation (in line with some literature), however, only until the age of about 50, after which the relationship becomes positive for higher age.

As mentioned before, the procedure to detect cheating follows the experiment of Fischbacher and Föllmi-Heusi (2013). Each subject rolls an ordinary six-sided die unobserved by the interviewer (or anybody else) and only reports the outcome to the interviewer. Thus, it is unknown if the individual participant is telling the truth about the outcome. The payoff for this simple one-shot game is linear to the outcome of the die, which provides a financial incentive to report a high number and, thus, receiving a high payoff. The exception is number "6" which yields a payoff of zero. Due to the undisclosed individual outcomes, the analysis can only be conducted for the distribution of individuals. We find that, on average, an outcome of 3.26 is reported, whereas the random result would be 2.5 (recoding die rolls from 0 to 5 ). Thus, there is clear cheating and (in line with the result from the meta-study) the claimed average profit of 0.76 units realizes just $30.4 \%$ of the maximum of 2.5 units; the maximum profit from cheating would be realized if everybody claims an outcome of 5 minus 2.5 for the outcome if everybody reports truly.

Literature. Our research relates to four strands of the cheating literature: (i) differences in the degree of cheating across countries; (ii) relation of cheating to corruption; (iii) relation of cheating to individual socio-demographic characteristics; and (iv) relation of cheating to situational characteristics and attitudes. Before we introduce this related literature, we note that cheating behavior in experiments seems to translate into real world behavior (Potters and Stoop, 2016; Hanna and Wang, 2017; Cohn and Maréchal, 2018; Dai et al., 2017).

(i) Empirical studies on cheating focus mainly on advanced economies, using students and lab experiments (see Abeler et al., 2019). From this perspective, we analyze a relatively rare sample, as we cover a relatively poor rural population in a field setting. Regarding the specific country, i.e. Thailand, we are not aware of any other study. However, multi-country studies do not find major differences regarding the degree of cheating across countries (e.g. Mann et al., 2016; Pascual-Ezama et al., 2015; Abeler et al., 2019). If there is a systematic influence, it may stem from higher development in the sense that the degree of cheating is lower in countries with higher income per capita (Hugh-Jones, 2016) and - relatedly - in countries with lower prevalence of rule violations (Gächter and Schulz, 2016). Given these factors, we expect that the degree of cheating in rural Thailand tends to be high compared to advanced economies. 
(ii) According to our knowledge, there is no study examining the relation between cheating and perceived corruption as we do within a household survey, but there are studies related to ours. Gächter and Schulz (2016) conduct the same experiment that we do in 23 countries and find that lying is more prevalent in countries where rule violations, including corrupt practices, are more prevalent. In contrast, they are not analyzing the effect of individually perceived corruption on cheating but the prevalence of corruption within a country. Houser et al. (2012) find that cheating is stronger after previously being treated unfairly and corruption certainly has an element of unfairness. In a similar manner, Drupp et al. (2019) find that persons tend to lie more if they face a regulator who they deem ill-regarded. Dong et al. (2012) show that willingness to engage in corruption increases if respective behavior of peers and others is observed. Kocher et al. (2017) analyze why people in groups tend to lie more than individuals and conclude that exchanging arguments that justify dishonest behavior and a change in the perception of norm compliance are important reasons for this "dishonesty shift." Thus, as discussed in the introduction, corruption might change the perception on norm violations.

(iii) The literature identifies a few relations between cheating and socio-demographic characteristics; however, these relations are rarely robust. Age seems to be rather negatively related to cheating, although this effect may be mainly driven by teenagers (GlätzleRützler and Lergetporer, 2015; Jacobsen et al., 2018). Women consistently cheat less than men, there is no relation to income (Rosenbaum et al., 2014; Jacobsen et al., 2018), and religiousness may reduce cheating slightly (Utikal and Fischbacher, 2013). While these findings result from a range of study formats to examine cheating (see Rosenbaum et al., 2014), the meta-study of Abeler et al. (2019) only focuses on the self-reported outcome format (as we use in our study). It finds that being male is the only variable robustly related to cheating. Age is related to less cheating, although only to a small degree. Otherwise, relations between cheating and socio-demographic variables do not seem to be robust (see also the representative study of Abeler et al. (2014)).

Still, even if relations between cheating and socio-demographic variables are not systematic across all kinds of studies, they may matter at the study level and they matter also for the measurement of corruption. Thus, it seems useful to control for these potential determinants.

(iv) Finally, there is an extensive literature relating cheating to situational circumstances or attitudes, which we address here selectively. For example, a role for risk attitude can be connected to the notion that "creative minds" cheat more (Gino and Ariely, 2012), as risk tolerance helps to "think outside the box." Bucciol et al. (2013) find that "unethical behavior" is related to being young, male, risk tolerant, and unemployed, among others. However, that research is not directly comparable to ours, as it analyzes a 
very specific cheating behavior in the field, i.e. not paying for public transport.

Many studies discuss implications when cheating has potential effects on other persons (e.g. Gneezy, 2005; Hurkens and Kartik, 2009; Erat and Gneezy, 2012; Cojoc and Stoian, 2014; Butler et al., 2016). There are also priming effects found, in that cheating drops when participants pay attention to the private environment instead of the business environment (Cohn et al., 2014). Moreover, cheating is stronger if it comes with higher incentives (Martinelli et al., 2018) and if people try to avoid losses (Grolleau et al., 2016). We acknowledge that these are strong determinants, but they do not play a role in our approach: our design purposely neither has implications for other persons, nor framing effects or potential losses.

However, our study is related to the intuition in some other studies in the literature. Our test of reputational concerns via attendance of others can be interpreted as a kind of monitoring that is known to reduce cheating (see Rosenbaum et al., 2014; Gneezy et al., 2018; Rilke et al., 2019), although Van de Ven and Villeval (2015) do not find such an effect in their specific setting.

Our study is organized in five more sections. Section 2 describes the survey, the standard cheating experiment, and the perceived corruption item, while Section 3 develops expectations about the relation between cheating and individual or situational characteristics. Respective results are reported in Section 4. Section 5 provides several robustness tests, and Section 6 concludes.

\section{Survey, cheating experiment and perceived corrup- tion}

This section provides a short description of the survey and the sample population (Section 2.1), the implementation of the cheating experiment (Section 2.2), the outcome of this experiment (Section 2.3), and responses to the items revealing perceived corruption (Section 2.4).

\subsection{About the household survey}

The basis of our research is a large household survey in northeast Thailand (the Thailand Vietnam Socio-economic Panel) conducted about every two years since 2007 (see e.g. Hardeweg et al., 2013). A total of three provinces in Thailand are covered. A three-stage sampling procedure is applied in order to representatively cover rural households in this area. We use 2013 survey data to obtain comprehensive information on individuals and their households, but only from the province of Ubon Ratchathani. We then conduct 
our lab-in-the-field experiment with these 860 individuals/households one year later. As connecting the data at the individual level over the two years is sometimes not possible, we use a reduced sample of still more than 500 individuals (between 18 and 85 years) for whom experimental results and individual information is available. However, there are no major economic differences between the full and the reduced sample, as we show below.

Descriptive statistics on socio-demographic characteristics of our main population, where full information is available, are provided in Table 1. Men make up 35\% of the sample, participants are on average 55 years old, and $76 \%$ are married. Education is limited as participants have an average of 5.5 years of schooling. The consumption and asset figures are household information, as this is the relevant economic unit. The measure is in log US-Dollar. As consumption - relative to income - can provide more reliable and useful information in poor rural areas, we rely on this variable. The lower part of the table provides information about additional variables that are introduced in Section 3. Then, we show the same descriptive information, first, for those 335 participants where we only have information about the experiment, and, second, for the full sample. The last column shows that differences between the two sub-samples with "full information" and "only experiments" are not very strong.

[Table 1 about here]

\subsection{Implementation of the "cheating experiment"}

The cheating experiment follows the example of Fischbacher and Föllmi-Heusi (2013). It is carried out by the interviewer, who conducts the entire interview, including experiments on risk attitude, time preference, and inequality aversion. In order to keep the whole survey feasible, the order and instructions are always the same; i.e. we neither change incentives, nor repeat the experiment (for the instructions see Appendix E). At the end of the complete interview, one of the four experiments (of which our cheating experiment is the third to be played) is randomly selected for payout. The expected payoff varies across these four experiments but is always on the order of 100 to 150 Thai Baht. In addition, there is a participation fee of 30 Baht, which is equivalent to the price of a regular meal. As the total interview takes about one hour, participation is attractive from a financial perspective. The theoretically expected payoff of 125 Baht equals almost a half-day wage for an unskilled laborer in that area of Thailand at that time.

The cheating experiment starts with the interviewer briefly explaining the experiment and providing the subjects, one from each household, a six-sided die with numbers one to six and a box. Then, the payoff table is shown to the subject and the payoff is explained, i.e. number one gets 50 Baht, number two gets 100 Baht until number five which gets 
250 Baht, while number six gets zero Baht. The expected payoff under the assumption of a fair-sided die is 125 Baht (750 divided by 6), thus providing an incentive for cheating behavior (Gibson et al., 2013; Gneezy et al., 2013). Thereafter, the interviewer asks the subject to secretly roll the die several times in the box, to keep the first number rolled in mind and to report this at the end to the interviewer, who then takes note of the outcome. For the subsequent analysis, we will order the die rolls by their payoffs, which means number 6 is recoded as the number 0 in the analysis.

\subsection{Descriptive results of the cheating experiment}

Each number has the same probability of being rolled, i.e. 16.7\%. However, people do not report such an equal distribution of outcomes, as we know from thousands of participants in earlier experiments. There are five well known stylized facts (Abeler et al., 2019): (i) Indeed, reported outcomes deviate systematically from random outcomes as the numbers with small payoffs are underrepresented while the numbers with high outcomes are overrepresented; (ii) subjects not only report the most attractive number, in our case the "5" but also frequently the number directly "below" it (here the "4"); (iii) it follows that the degree of cheating is below the maximum possible, the stylized fact is about one-quarter of the maximum; (iv) men cheat more than women; and, finally, (v) older people cheat less than the young, although only to a limited extent.

Given these five stylized facts, the outcomes for our sample are reassuring as they largely confirm these. The outcomes for our sample are presented in the left part of Figure 1, separately for women and men. It is obvious that participants do cheat, that the second-best outcome is also over-represented, that the degree of cheating is limited (about 30\% of the maximum), and that men cheat more than women. The right part of Figure 1 shows responses as compiled by the meta-study; comparing the left and right parts of Figure 1, one can see the very nice fit of our experiment into the pattern of earlier experiments. While we find a negative relation between cheating and age only until the age of 50, the first four facts clearly indicate that behavior in our sample is regular and, hence, further examinations can be largely generalized.

[Figure 1 about here]

\subsection{Question and descriptive results on perceived corruption}

Perceived corruption is derived from the answers to the survey question "There could be many reasons why not all government money reaches the targeted poor households. Which of the following do you think are the two main reasons why money may not reach the poor?" Survey participants can choose a first and a second main reason from the 
following four alternatives: "government procedures are expensive," "government officers are inefficient," "corruption," and "none of these reasons." We define our measure of perceived corruption as a dummy variable, i.e. respondents mention the corruption item as either a first or second main reason, which applies to $75 \%$ of respondents. The bivariate relation between the degree of cheating and the share of perceived corruption (relative to the average) is shown in Figure 2.

[Figure 2 about here]

By-and-large, there is a positive relation, i.e. a larger share of perceived corruption is related to a higher degree of cheating. However, the first group, i.e. those receiving a payoff of zero, seems to be different from the others. While the expected pattern holds nicely for die rolls from 1 to 5 , this relation breaks down for those rolling a 6 . There is a group of people, who, despite perceiving a large amount of corruption, decide for themselves to stay honest. Thus, they seem to draw a different conclusion about perceived corruption than does the vast majority. They might want to counteract the wrongdoing of their political leaders or want to feel morally superior to others because of self-image concerns. Regardless, we exclude those individuals from further analysis as they show no cheating in reaction to perceiving corruption.

Alternatively, we test a two-step decision model, where the first step is that perceived corruption leads to either less or more cheating. The problem with this approach is that the observed characteristics of those who report having rolled a 6 are not much different from the others (see Table 2). Moreover, we do not observe variation among those who cheat less. Overall, this modeling approach does not seem appropriate in our case, which is why we continue with focusing on the vast majority of observations. However, from an ethical point of view, it seems noteworthy that some individuals do not compromise even when they perceive corruption. This group is probably larger than the share we can identify within the sample, as there may be others who rolled lower numbers but would also report the truth had they had rolled a 6 .

[Table 2 about here]

\section{Expectations about potentially covarying charac- teristics}

In this section, we develop ex ante hypotheses about characteristics that may be related to cheating and, thus, should be controlled for when analyzing the relation between cheating and corruption (Section 3.1). The variables measuring these characteristics are discussed in Section 3.2. 


\subsection{Hypotheses about the role of individual characteristics}

Evidence on the relationships between cheating and individual or situational characteristics is quite thin. This is surprising as there appear to be many plausible relations between several of these characteristics and cheating. A reason for the lack of evidence could be the fact that most experiments are conducted in the lab with students, meaning that there is not much variation between subjects. In the following, we first discuss hypotheses based on socio-demographic characteristics and then we develop hypotheses based on individual attitudes as well as situational characteristics.

(i) Our first hypothesis is that men will cheat more than women, because this relation is generally found (e.g. Houser et al., 2012) and also found with respect to the specific experiment applied here (Abeler et al., 2019).

(ii) Following the metastudy of Abeler et al. (2019), we expect a slightly negative relation between cheating and age.

(iii) One could argue that having children provides a similar influence to that of religion, as adults who are educating children may be more aware that cheating violates an accepted norm. As it is difficult to infer precisely who is (or is not) involved in education (inside or outside the household), we take an alternative proxy for having children, i.e. being married.

(iv) A kind of ambiguous relation may apply to education, as, on the hand, the better educated are expected to be more aware that cheating is a norm violation, but on the other hand, they may also better realize the economic advantage of cheating (literature is inconsistent, following Jackson et al. (2002).

(v) The relation of cheating to consumption (or income) is potentially ambiguous as well. Individuals with higher income have a lower financial incentive to cheat. At the same time, Abeler et al. (2014) argue that there may be reverse causality in the sense that individuals have realized higher income because they are less concerned about cheating.

(vi) Finally, we look at wealth, whose relation to cheating may be the same as that regarding consumption/income or education. We rely mainly on the procedure that is suggested for poor rural populations where wealth is difficult to measure in money terms: we enumerate all assets with positive value and take the number of these assets as a wealth indicator (e.g. Vyas and Kumaranayake, 2006). However, as the ex ante expectation on the influence of wealth on cheating is ambiguous (as aforementioned), we also run a factor analysis in order to usefully aggregate assets with potentially different influences on cheating. We use the two most important factors in our analysis: factor 1 represents mainly durable consumption goods, while factor 2 represents investment goods for agriculture. Details on the construction are provided in Appendix A.

Beyond these socio-demographic characteristics, there may be individual attitudes 
or situational characteristics that are related to cheating. Here, we discuss risk taking, confidence in own decision making, and trust in people outside the village as potentially relevant attitudes; the exact survey items are introduced in Section 3.2. Finally, we look at the number of people attending the experiment as a situational characteristic.

(vii) Regarding risk-taking, we argue that cheating requires an element of going against societal norms to some extent and this may be easier for risk tolerant individuals.

(viii) Regarding confidence, we hypothesize that confident individuals believe in their ability, including earning money, and, thus, are less reliant on cheating as a way to gain a (financial) advantage. In this sense, confident individuals can afford to be more honest than others.

(ix) Regarding trust in other people, the expectation is that individuals who trust others more, will cheat less, as trust relies on the belief that others do not cheat.

(x) Finally, the number of attending people, excluding the interviewer and participant, is analyzed, because people care about their reputation to be honest Abeler et al. (2019). The argument here is that others present during the experiment may doubt the highest outcome, such that participants may shy away from cheating if there are observers.

\subsection{Description of individual attitudes}

In this section, we describe the measurement and distribution of the three aforementioned attitudes above as well as the number of people attending the experiment.

Risk taking. Risk taking is measured by a multiple price list (MPL) following the approach of Holt and Laury (2002). A 50:50-lottery between 0 and 300 THB is fixed while the safe amount is increasing from 0 to 190 THB. The outcome of this question is presented in Figure C.1. The explanatory power of this measure is shown for an earlier wave of this household survey in Hardeweg et al. (2013).

Confidence. Here we rely on the question whether participants feel confident when they make an agricultural decision. The question intentionally refers to a concrete field of decision making. Agriculture is the best choice in this respect because the survey takes place in a rural area. Accordingly, almost all participants have some experience in agriculture, at least for the purpose of subsistence production. The coding ranges from 1 for being "always confident" to 5 for being "never confident." The distribution of answers is shown in Figure C.2. Most people have a mild level of confidence, with extreme values reported by a few participants.

Trust in other people. We use a survey item that asks how much respondents "trust people outside the own village." The distribution is depicted in Figure C.3. As higher numbers indicate more trust, the clear majority of respondents expresses no or little trust in strangers from outside their own village. 
Number of attendants. One last piece of information that the interviewers note is the number of people attending the interview (excluding interviewer and the participant); this occurs at the point of time when our experiment is conducted. Attendance of others can happen because the interview takes place in the household's dwelling and there are either household members or guests around as the dwellings are usually open. It is important to highlight that the nature of the experiment is not announced in advance. Accordingly, there is no strong concern of an endogenously determined number of attendants (an issue we investigate further in robustness Section 5.3). Figure 3 provides simple descriptive statistics of how many people are present at the time the experiments are conducted. As shown (see also the descriptive statistics in Table 1), there are attendants in $65 \%$ of cases and the average number, conditional on the case of attendance, exceeds two persons. This number is 2.15 for women and 2.28 for men, the difference is not statistically significant (two-sided t-test, $\mathrm{p}=0.5$ ).

[Figure 3 about here]

\section{Empirical approach and results}

We report results in three steps. First, Section 4.1 introduces the empirical approach for the multivariate analysis, Section 4.2 contains the main results, and Section 4.3 complements these with further analyses.

\subsection{Empirical approach}

Our dependent variable of "cheating" is a discrete ordered variable. We know that this variable is neither uniformly nor normally distributed, with specific numbers mentioned more frequently than others (see Section 2.3). As we exclude the group with a payoff of zero (see Section 2.4), higher payoffs also mean that these groups cheat with a higher probability than others. Thus, first, due to the incentives provided, these groups are larger than others; second, the information about non-cheating vs. cheating is less precise as these groups increasingly comprise non-cheaters and cheaters. Consequently, overweighting the groups with lower payoffs relative to the higher payoff groups corrects for the explained distortions.

Thus, we conduct estimates weighted by the inverse difference between observed and theoretical frequencies in each category, standardized by the share of honest persons. More details on how this procedure is implemented here are provided in Appendix B. The important insights are, first, that this procedure is more convincing from an economic point of view than the alternatives and, second, that applying the weighting approach is 
helpful for revealing the influence of corruption and attendance on cheating more precisely, as we demonstrate in robustness testing in Section 5.1.

\subsection{Explaining cheating behavior: main results}

We now apply the multivariate weighting approach to our variables of interest, as introduced by the hypotheses in Section 3.1. In order to limit the number of variables, we rely on the consumption variable but omit assets variables as information in these variables is clearly correlated. Column (1) of Table 3 presents the full specification with all considered variables, of which three are statistically significant at least at the $5 \%$ level and two more at the $10 \%$ level. We shortly discuss these outcomes:

[Table 3 about here]

(i) Our main variable of interest, i.e. perceived corruption, is positively related to cheating. The coefficient is highly significant. On average, perceiving corruption increases the reported die number by almost 0.35 ; about 0.26 of the standard deviation.

(ii) Age has a non-linear relation with cheating. In line with the literature, cheating declines with age (significant at the $10 \%$ level); however, older people in our sample, i.e. those beyond about 50 years old, cheat more with higher age, and this effect is significant at the $5 \%$ level.

(iii) The relation of cheating to risk taking is positive and significant at the $10 \%$ level. The most risk tolerant persons report die rolls that are, on average, 0.28 larger than those of the least tolerant persons. This confirms our hypothesis that risk tolerant people are less afraid - relative to risk averse participants - that cheating is against the norm.

(iv) A larger number of attendants decreases the degree of cheating, significantly at the $5 \%$ level. This means that playing the game while others observe the participants reduces the probability of cheating. This is consistent with the model of Abeler et al. (2019).

Finally, we would like to mention that most of the statistically insignificant coefficients have the expected sign: the coefficient of male is positive, the ones on married and trust are negative - all as expected; only the positive coefficient on confidence contradicts the hypothesis. The coefficients on education and consumption were ex ante undetermined and are positive.

The model of Abeler et al. (2019) contains two preferences to explain observable cheating behavior, i.e. a "preference for honesty" and a "preference for reputation to be seen as honest." While the latter preference, i.e. to be seen as honest, seems to be confirmed by the negative effect of number of attendants, the other significant variables 
can be linked nicely to the preference for honesty. Both a higher degree of perceived corruption and a higher degree of risk tolerance tend to undermine honest behavior.

\subsection{Further analyses}

In further columns, we dig deeper into the effect of assets on cheating (as consumption has no effect) and the effect of attendance. In column (2) of Table 3, we consider the number of (valuable) assets a household has and, as can be seen, having more assets is significantly and negatively related to cheating. Column (3) shows a regression where we substitute the number of assets by the two strongest asset components of a factor analysis. It seems that owning durable consumption goods tends to be negatively related to cheating while owning agricultural assets depicts a positive, albeit much smaller and insignificant, coefficient. In column (4), we take the former specification (1) but substitute the number of attendants with a binary variable indicating whether there are any attendants or not. Results remain almost unchanged. In all specifications, the remaining coefficients are largely unaffected. Finally, in column (5), we show that the above main findings also hold when only the so far significant variables $(\mathrm{p}<0.1)$ of specification $(4)$ are considered. The coefficient on the corruption variable increases, while other coefficient sizes and their level of statistical significance change only slightly.

Overall, we identify a set of variables that are related to cheating behavior and, thus, should be controlled for when analyzing the relation between corruption and cheating behavior.

\section{Robustness tests}

In the robustness section, we address three issues. First, different empirical models are applied, confirming that weighted estimates are superior to alternatives (Section 5.1). Second, we analyze cheating behavior by defining different forms of cheating behavior, i.e. we modify the LHS-variable (Section 5.2). Third, we split the sample regarding whether there were attendants at the cheating experiment or not (Section 5.3).

\subsection{Alternative empirical models}

While the presented weighted linear regression model seems to be justified from an ex ante perspective, here we show that alternative empirical models provide largely the same information. This may be reassuring, however, the alternatives obviously deliver less significant coefficients. In Table 4, we present the results for four such models. In column (1), we also use a weighted OLS, however, here we only correct for the deviations 
from the theoretical population distribution, such that the five groups receive the same weight in the regression. The weights here are roughly 3 to 1 from group 1 to group 5, while the span of weight is 10 to 1 in our main specification. In column (2) we use an interval regression (assuming that the cheating variable is a continuous variable within classes), and in column (3) an ordered logit regression (in order to take account of the ordered nature of the experimental outcome variable). We also show the result of a standard OLS-regression in column (4).

[Table 4 about here]

The estimates demonstrate that the preferred weighted regression approach is superior to the alternatives shown here, regarding its explanatory power. In the first three columns, the corruption variable remains marginally significant while most other coefficients are insignificant. As expected, the standard OLS has even less explanatory power.

\subsection{Results for different definitions of the cheating variable}

In this part, we test the robustness of our main findings with respect to variations of the underlying endogenous variable. We aggregate cheating categories to dummies in order to clarify the empirical concept of cheating and assume that individuals reporting higher outcomes are more likely to have cheated. For example, we form a dummy, pay $45=1$, if people have a reported outcome of 4 or 5 , while all other outcomes are set to zero. The hypothesis is that people in pay $45=1$ have a higher lying potential and, thus, the lying effects might be clearer than in Table 3. However, the result shown in Table 5, column (1), does not reveal any new relations.

[Table 5 about here]

Of course, we do not know who is truly cheating and, thus, we cannot know the best cut-off to distinguish between a high and a low probability of cheating. Therefore, we apply different cut-offs. Besides pay45, we merge the outcomes of 3, 4 and 5 into another cheating category. Finally, 2 to 5 are combined. We test whether pay45, pay345, or pay2345 allows the best modelling of cheating. Looking at the results in Table 5, we do not discover fundamental differences. The signs are always the same for all variables. The degree of significance is larger for pay345 and pay2345 compared to pay45. Therefore, these results confirm our main findings in Table 3.

\subsection{Considering attendance vs. no attendance}

We consider the case of attendants watching the experiment largely as an exogenous event. This is justified because participants did not know in advance that there would be 
an experiment on cheating behavior. In fact, it seems plausible that participants in the study may differ in their characteristics, even with respect to allowing for or potentially aiming for attendants, or the opposite. In case of large differences between the groups of attendants and the roughly one-third of participants without attendants, these differences may be the drivers behind attendance and, thus, of interest for understanding cheating behavior.

Therefore, we form two groups regarding whether the experiment was conducted either (a) with attendants or (b) without attendants. First, we test whether these groups differ substantially in their characteristics. This is generally not the case (as shown in Appendix Table E.1) and in the two cases of borderline significant differences, these do not matter in economic terms. Thus, second, we run the main regressions as presented in Table 3 for these two subgroups. Results in Table 6 show that the sign and size of coefficients is qualitatively similar to results in Table 3, although with some heterogeneity across groups. Moreover, the level of significance is lower, particularly for group (a), and accordingly the adjusted R-squared is several times higher for group (b) than for group (a). This may cautiously indicate that these participants feel freer in behaving according to their preferences while the situation of attendants observing the experimental outcome may lead to a moderated outcome. Interestingly, the effect of risk taking is larger in group (a) than for the general sample, possibly because these participants are less afraid to be caught or seen as liars, but negative, albeit not significant, for group (b).

[Table 6 about here]

\section{Conclusion}

Understanding cheating behavior is receiving increased attention. We contribute to this literature by considering the relation between perceived corruption and cheating, while simultaneously controlling for a wide range of socio-demographic and situational characteristics. Specifically, we conduct a standard lab-in-the-field cheating experiment in a setting where corruption plays a large role, i.e. in rural Thailand. In order to demonstrate that results from this study may be generalizable, we largely reproduce the five stylized facts found in a wealth of studies. Thus, we seem to have a reliable basis supporting that our novel research helps to better understand cheating behavior beyond just the specific sample.

Our main finding is that perceived corruption is strongly and robustly related to more cheating, as predicted by the theoretical literature on corruption, which states that corruption undermines ethical behavior in general. In order to show the robustness of this finding, we consider a large set of potentially confounding determinants of cheating. These 
determinants reflect the theoretical set-up of Abeler et al. (2019), that a preference for honesty and a preference for being seen as honest are necessary to explain observable behavior. Honesty seems to be supported by a medium age (and, in one specification, by more affluence), but undermined by more risk tolerance. Finally, as hypothesized but not yet experimentally shown in a comprehensive field experiment (to the best of our knowledge), more attendants lead to less cheating, most probably by increasing reputational concerns.

The policy consequences of these findings appear straightforward. Any measure that succeeds in fighting corruption will probably positively affect honest behavior, not just in the experiment but plausibly also in other domains and in real world behavior in general (acknowledging that experimentally revealed cheating predicts real world behavior). Moreover, transparency of decision processes (here approximated by attendants), some experience of decision makers (approximated by medium age), and potentially sufficient remuneration of decision makers (creating an element of affluence) seem to help support honest decision making. 


\section{References}

Abeler, Johannes, Anke Becker, and Armin Falk, 2014, "Representative evidence on lying costs." Journal of Public Economics, 113, 96-104.

Abeler, Johannes, Daniele Nosenzo, and Collin Raymond, 2019, "Preferences for truth-telling." Econometrica, 87 (4), 1115-1153.

Aidt, Toke S., 2003, "Economic analysis of corruption: a survey." The Economic Journal, 113 (491), F632-F652.

Bucciol, Alessandro, Fabio Landini, and Marco Piovesan, 2013, "Unethical behavior in the field: Demographic characteristics and beliefs of the cheater." Journal of Economic Behavior and Organization, 93, 248-257.

Butler, Jeff, Paola Giuliano, and Luigi Guiso, 2016, "Trust and cheating." The Economic Journal, 126 (595), 1703-1738.

Cohn, Alain and Michel André Maréchal, 2018, "Laboratory measure of cheating predicts school misconduct." The Economic Journal, 128 (615), 2743-2754.

Cohn, Alain, Ernst Fehr, and Michel André Maréchal, 2014, "Business culture and dishonesty in the banking industry." Nature, 516 (7529), 86.

Cojoc, Doru and Adrian Stoian, 2014, "Dishonesty and charitable behavior." Experimental Economics, 17 (4), 717-732.

Dai, Zhixin, Fabio Galeotti, and Marie Claire Villeval, 2017, "Cheating in the lab predicts fraud in the field: An experiment in public transportation." Management Science, 64 (3), 1081-1100.

Dimant, Eugen and Guglielmo Tosato, 2018, "Causes and effects of corruption: what has past decade's empirical research taught us? A Survey." Journal of Economic Surveys, 32 (2), 335-356.

Dong, Bin, Uwe Dulleck, and Benno Torgler, 2012, "Conditional corruption." Journal of Economic Psychology, 33 (3), 609-627.

Drupp, Moritz A., Menusch Khadjavi, and Martin F. Quaas, 2019, "Truth-telling and the regulator. Experimental evidence from commercial fishermen." European Economic Review, 120, 103310.

Erat, Sanjiv and Uri Gneezy, 2012, "White lies." Management Science, 58 (4), 723-733.

Fischbacher, Urs and Franziska Föllmi-Heusi, 2013, "Lies in disguise - an experimental study on cheating." Journal of the European Economic Association, 11 (3), 525-547.

Gächter, Simon and Jonathan F. Schulz, 2016, "Intrinsic honesty and the prevalence of rule violations across societies." Nature, 531 (7595), 496.

Gibson, Rajna, Carmen Tanner, and Alexander F. Wagner, 2013, "Preferences for truthfulness: Heterogeneity among and within individuals." American Economic Review, 103 (1), 532-48. 
Gino, Francesca and Dan Ariely, 2012, "The dark side of creativity: original thinkers can be more dishonest." Journal of Personality and Social Psychology, 102 (3), 445.

Glätzle-Rützler, Daniela and Philipp Lergetporer, 2015, "Lying and age: An experimental study." Journal of Economic Psychology, 46, 12-25.

Gneezy, Uri, 2005, "Deception: The role of consequences." American Economic Review, 95 (1), 384-394.

Gneezy, Uri, Agne Kajackaite, and Joel Sobel, 2018, "Lying Aversion and the Size of the Lie." American Economic Review, 108 (2), 419-53.

Gneezy, Uri, Bettina Rockenbach, and Marta Serra-Garcia, 2013, "Measuring lying aversion." Journal of Economic Behavior and Organization, 93, 293-300.

Grolleau, Gilles, Martin G. Kocher, and Angela Sutan, 2016, "Cheating and loss aversion: Do people cheat more to avoid a loss?" Management Science, 62 (12), 3428-3438.

Hanna, Rema and Shing-Yi Wang, 2017, "Dishonesty and selection into public service: Evidence from India." American Economic Journal: Economic Policy, 9 (3), 262-90.

Hardeweg, Bernd, Lukas Menkhoff, and Hermann Waibel, 2013, "Experimentally validated survey evidence on individual risk attitudes in rural Thailand." Economic Development and Cultural Change, 61 (4), 859-888.

Holt, Charles A. and Susan K. Laury, 2002, "Risk aversion and incentive effects." American Economic Review, 92 (5), 1644-1655.

Houser, Daniel, Stefan Vetter, and Joachim Winter, 2012, "Fairness and cheating." European Economic Review, 56 (8), 1645-1655.

Hugh-Jones, David, 2016, "Honesty, beliefs about honesty, and economic growth in 15 countries." Journal of Economic Behavior and Organization, 127, 99-114.

Hurkens, Sjaak and Navin Kartik, 2009, "Would I lie to you? On social preferences and lying aversion." Experimental Economics, 12 (2), 180-192.

Jackson, Chris J., Stephen Z. Levine, Adrian Furnham, and Nicole Burr, 2002, "Predictors of cheating behavior at a university: A lesson from the psychology of work." Journal of Applied Social Psychology, 32 (5), 1031-1046.

Jacobsen, Catrine, Toke Reinholt Fosgaard, and David Pascual-Ezama, 2018, "Why do we lie? A practical guide to the dishonesty literature." Journal of Economic Surveys, 32 (2), 357-387.

Kajackaite, Agne and Uri Gneezy, 2017, "Incentives and cheating." Games and Economic Behavior, 102, 433-444.

Kocher, Martin G., Simeon Schudy, and Lisa Spantig, 2017, "I lie? We lie! Why? Experimental evidence on a dishonesty shift in groups." Management Science, 64 (9), 3995-4008.

Lambsdorff, Johann Graf, The institutional economics of corruption and reform: Theory, evidence and policy, Cambridge university press, 2007. 
Mann, Heather, Ximena Garcia-Rada, Lars Hornuf, Juan Tafurt, and Dan Ariely, 2016, "Cut from the same cloth: Similarly dishonest individuals across countries." Journal of Cross-Cultural Psychology, 47 (6), 858-874.

Martinelli, César, Susan W. Parker, Ana Cristina Pérez-Gea, and Rodimiro Rodrigo, 2018, "Cheating and incentives: Learning from a policy experiment." American Economic Journal: Economic Policy, 10 (1), 298-325.

Pascual-Ezama, David, Toke R. Fosgaard, Juan Camilo Cardenas, Praveen Kujal, Robert Veszteg, Beatriz Gil-Gómez de Liaño, Brian Gunia, Doris Weichselbaumer, Katharina Hilken, Armenak Antinyan et al., 2015, "Context-dependent cheating: Experimental evidence from 16 countries." Journal of Economic Behavior and Organization, 116, 379-386.

Potters, Jan and Jan Stoop, 2016, "Do cheaters in the lab also cheat in the field?" European Economic Review, 87, 26-33.

Rilke, Rainer Michael, Anastasia Danilov, Ori Weisel, Shaul Shalvi, and Bernd Irlenbusch, "When leading by example leads to less corrupt collaboration." 2019. Mimeo.

Rosenbaum, Stephen Mark, Stephan Billinger, and Nils Stieglitz, 2014, "Let's be honest: A review of experimental evidence of honesty and truth-telling." Journal of Economic Psychology, 45, $181-196$.

Utikal, Verena and Urs Fischbacher, 2013, "Disadvantageous lies in individual decisions." Journal of Economic Behavior and Organization, 85, 108-111.

Van de Ven, Jeroen and Marie Claire Villeval, 2015, "Dishonesty under scrutiny." Journal of the Economic Science Association, 1 (1), 86-99.

Vyas, Seema and Lilani Kumaranayake, 2006, "Constructing socio-economic status indices: how to use principal components analysis." Health Policy and Planning, 21 (6), 459-468.

World Bank Worldwide Governance Indicators

World Bank Worldwide Governance Indicators, www. govindicators. org 2018. Accessed: 2018. 


\section{Tables and Figures}

Table 1: Descriptive Statistics

\begin{tabular}{lcccc}
\hline & Full Information & Only Experiment & Full Sample & $\begin{array}{c}\text { Difference } \\
\text { Only - Full Info }\end{array}$ \\
\hline Male & 0.35 & 0.40 & 0.37 & 0.06 \\
Age & 55.24 & 49.38 & 52.97 & $-5.86^{* * *}$ \\
Married & 0.76 & 0.82 & 0.79 & $0.06^{* *}$ \\
Education & 5.47 & 6.64 & 5.92 & $1.17^{* * *}$ \\
Consumption per Cap. & 7.09 & 7.09 & 7.09 & -0.01 \\
Asset Value & 8.43 & 8.65 & 8.51 & $0.21^{* *}$ \\
Asset Index, 1. Factor & -0.07 & 0.09 & -0.02 & 0.15 \\
Asset Index, 2. Factor & -0.03 & 0.14 & 0.04 & 0.17 \\
Risk Taking, MPL & 10.96 & 11.08 & 10.99 & 0.12 \\
Confidence & 2.42 & 2.42 & 2.42 & 0.00 \\
Trust in Outsiders & 1.61 & 1.66 & 1.63 & 0.05 \\
Attendants & 1.40 & 1.57 & 1.47 & 0.17 \\
Attendants Dummy & 0.64 & 0.67 & 0.65 & 0.03 \\
\hline Observations & 523 & 335 & 860 & 858 \\
\hline
\end{tabular}

Variables: Male( $0=$ female; $1=$ male), Age(years), Married( $0=$ no; $1=$ yes), Education(years), Consumption per Cap.(annually, in log US-Dollar), Asset Value(total value of all hh assets), Asset Indices(derived via pca), Risk Taking, MPL(switching row from lottery to safe value, from 1 to 21), Confidence(in agricultural decisions from 1-always confident to 5 -never confident), Trust in Outsiders(1-trust them not at all to 5 -trust them a lot), Attendants(no. of attendants), Attendants Dummy ( $0=$ no attendants; $1=$ attendants), Perceived Corruption $(0=$ no; $1=$ yes $)$.

${ }^{*} \mathrm{p}<0.10,{ }^{* *} \mathrm{p}<0.05,{ }^{* * *} \mathrm{p}<0.01$ 
Figure 1: Empirical Distributions of Standardized Cheating by Sex

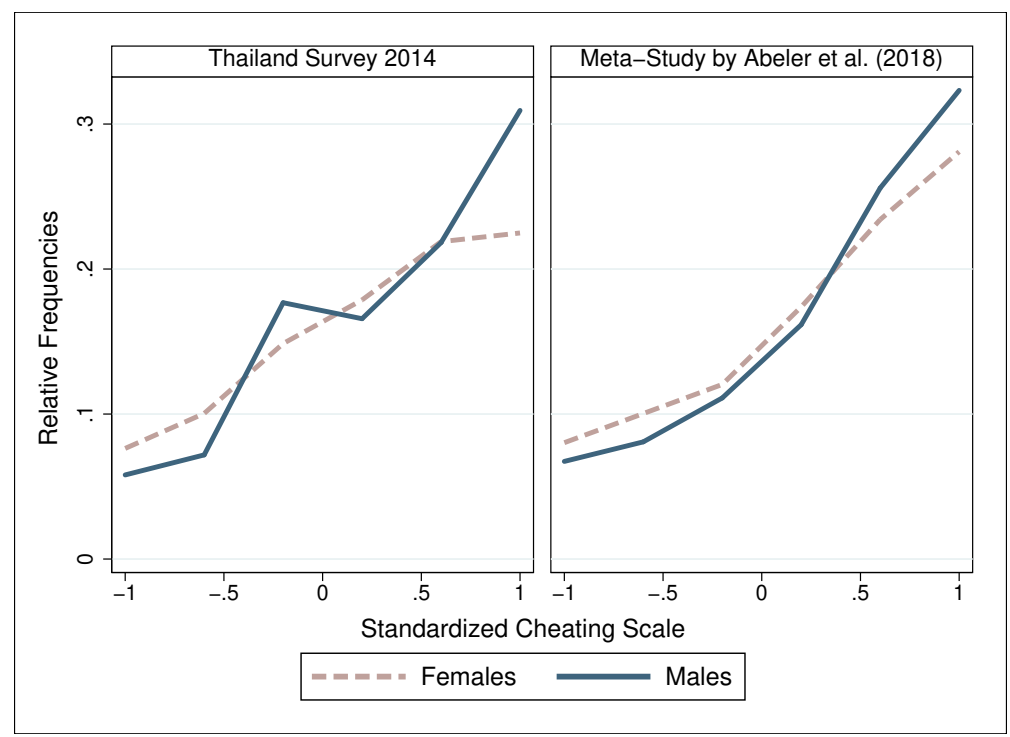

Note: Standardized scale from lowest to highest payoff. In the case of the left panel this implies from rolling a 6 to rolling a 5 .

Figure 2: Perceived Corruption for Each Level of Reporting

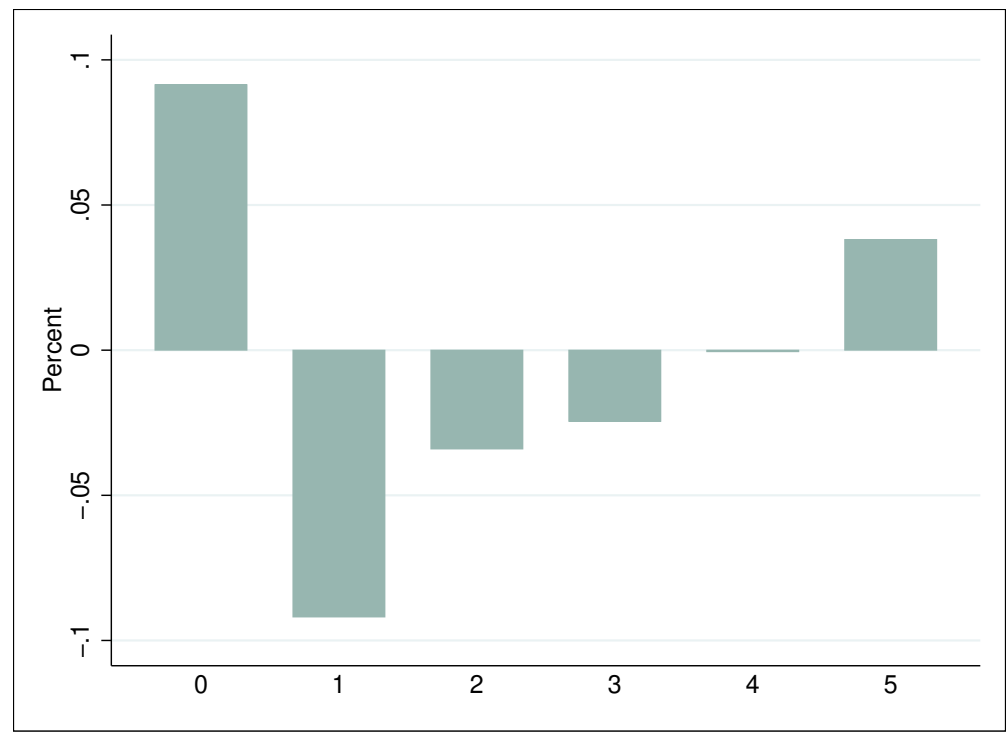

Note: Share of people who perceive corruption at each level of reporting as deviation from the mean perceived corruption. 
Table 2: Descriptive Statistics - Group who reported a 6 (0 payoff) vs. Others

\begin{tabular}{lcccc}
\hline & Full Information & Reported 6 & Others & Difference \\
\hline Male & 0.35 & 0.47 & 0.34 & $-0.14^{*}$ \\
Age & 55.24 & 52.28 & 55.46 & 3.18 \\
Married & 0.76 & 0.81 & 0.76 & -0.04 \\
Education & 5.47 & 5.81 & 5.45 & -0.36 \\
Consumption per Cap. & 7.09 & 7.21 & 7.08 & -0.13 \\
Asset Value & 8.43 & 8.76 & 8.41 & -0.35 \\
Asset Index, 1. Factor & -0.07 & 0.29 & -0.09 & -0.39 \\
Asset Index, 2. Factor & -0.03 & 0.30 & -0.06 & -0.36 \\
Risk Taking, MPL & 10.96 & 9.75 & 11.05 & 1.30 \\
Confidence & 2.42 & 2.17 & 2.43 & 0.26 \\
Trust in Outsiders & 1.61 & 1.69 & 1.60 & -0.09 \\
Attendants & 1.40 & 1.42 & 1.40 & -0.01 \\
Attendants Dummy & 0.64 & 0.67 & 0.64 & -0.03 \\
Perceived Corruption & 0.74 & 0.83 & 0.74 & -0.10 \\
\hline Observations & 523 & 36 & 487 & 523 \\
\hline
\end{tabular}

Variables: Male( $0=$ female; $1=$ male), Age(years), Married( $0=$ no; $1=$ yes), Education(years), Consumption per Cap.(annually, in log US-Dollar), Asset Value(total value of all hh assets), Asset Indices(derived via pca), Risk Taking, MPL(switching row from lottery to safe value, from 1 to 21), Confidence(in agricultural decisions from 1-always confident to 5 -never confident), Trust in Outsiders(1-trust them not at all to 5 -trust them a lot), Attendants(no. of attendants), Attendants Dummy( $0=$ no attendants; $1=$ attendants $)$, Perceived Corruption $(0=$ no; $1=$ yes $)$.

${ }^{*} \mathrm{p}<0.10,{ }^{* *} \mathrm{p}<0.05,{ }^{* * *} \mathrm{p}<0.01$

Figure 3: Number of Attendants

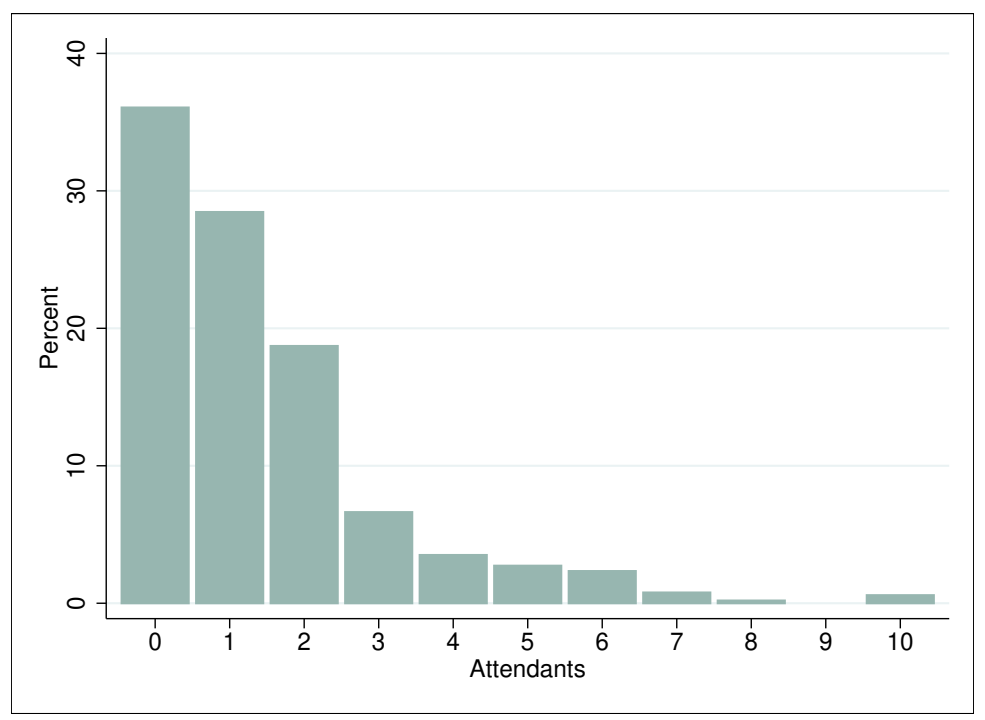


Table 3: Regression Estimates with Weights

\begin{tabular}{|c|c|c|c|c|c|}
\hline & (1) & (2) & (3) & (4) & (5) \\
\hline Perceived Corruption & $\begin{array}{c}0.343^{* *} \\
(0.146)\end{array}$ & $\begin{array}{c}0.277^{*} \\
(0.146)\end{array}$ & $\begin{array}{c}0.321^{* *} \\
(0.146)\end{array}$ & $\begin{array}{c}0.309^{* *} \\
(0.145)\end{array}$ & $\begin{array}{c}0.358^{* *} \\
(0.144)\end{array}$ \\
\hline Male & $\begin{array}{c}0.050 \\
(0.148)\end{array}$ & $\begin{array}{c}0.063 \\
(0.147)\end{array}$ & $\begin{array}{c}-0.003 \\
(0.149)\end{array}$ & $\begin{array}{c}0.031 \\
(0.148)\end{array}$ & \\
\hline Age & $\begin{array}{c}-0.074^{*} \\
(0.039)\end{array}$ & $\begin{array}{c}-0.065^{*} \\
(0.038)\end{array}$ & $\begin{array}{c}-0.060 \\
(0.039)\end{array}$ & $\begin{array}{c}-0.079^{* *} \\
(0.039)\end{array}$ & $\begin{array}{c}-0.075^{* *} \\
(0.036)\end{array}$ \\
\hline $\mathrm{Age}^{2}$ & $\begin{array}{c}0.001^{* *} \\
(0.000)\end{array}$ & $\begin{array}{c}0.001 * \\
(0.000)\end{array}$ & $\begin{array}{c}0.001 * \\
(0.000)\end{array}$ & $\begin{array}{c}0.001^{* *} \\
(0.000)\end{array}$ & $\begin{array}{c}0.001^{* *} \\
(0.000)\end{array}$ \\
\hline Married & $\begin{array}{c}-0.215 \\
(0.166)\end{array}$ & $\begin{array}{c}-0.162 \\
(0.165)\end{array}$ & $\begin{array}{c}-0.245 \\
(0.169)\end{array}$ & $\begin{array}{c}-0.211 \\
(0.166)\end{array}$ & \\
\hline Education & $\begin{array}{c}0.013 \\
(0.026)\end{array}$ & $\begin{array}{c}0.033 \\
(0.025)\end{array}$ & $\begin{array}{c}0.038 \\
(0.027)\end{array}$ & $\begin{array}{c}0.014 \\
(0.026)\end{array}$ & \\
\hline Consumption per Cap. & $\begin{array}{c}0.026 \\
(0.120)\end{array}$ & & & $\begin{array}{c}0.027 \\
(0.120)\end{array}$ & \\
\hline Risk Taking, MPL & $\begin{array}{c}0.014 \\
(0.009)\end{array}$ & $\begin{array}{l}0.014^{*} \\
(0.009)\end{array}$ & $\begin{array}{c}0.014^{*} \\
(0.009)\end{array}$ & $\begin{array}{c}0.013 \\
(0.009)\end{array}$ & $\begin{array}{c}0.011 \\
(0.008)\end{array}$ \\
\hline Confidence & $\begin{array}{c}0.038 \\
(0.067)\end{array}$ & $\begin{array}{c}0.058 \\
(0.067)\end{array}$ & $\begin{array}{c}0.061 \\
(0.068)\end{array}$ & $\begin{array}{c}0.033 \\
(0.067)\end{array}$ & \\
\hline Trust in Outsiders & $\begin{array}{c}-0.122 \\
(0.085)\end{array}$ & $\begin{array}{c}-0.131 \\
(0.084)\end{array}$ & $\begin{array}{c}-0.129 \\
(0.085)\end{array}$ & $\begin{array}{c}-0.114 \\
(0.086)\end{array}$ & \\
\hline Attendants & $\begin{array}{c}-0.092^{* *} \\
(0.041)\end{array}$ & $\begin{array}{c}-0.102^{* *} \\
(0.040)\end{array}$ & $\begin{array}{c}-0.093^{* *} \\
(0.041)\end{array}$ & & $\begin{array}{c}-0.117^{* * *} \\
(0.039)\end{array}$ \\
\hline Asset Value & & $\begin{array}{r}-0.095^{*} \\
(0.049)\end{array}$ & & & $\begin{array}{c}-0.071 \\
(0.046)\end{array}$ \\
\hline Asset Index, 1. Factor & & & $\begin{array}{r}-0.060 \\
(0.038)\end{array}$ & & \\
\hline Asset Index, 2. Factor & & & $\begin{array}{c}0.024 \\
(0.043)\end{array}$ & & \\
\hline Attendants Dummy & & & & $\begin{array}{c}-0.329^{* *} \\
(0.144)\end{array}$ & \\
\hline Constant & $\begin{array}{l}3.911^{* * *} \\
(1.263)\end{array}$ & $\begin{array}{l}4.560^{* * *} \\
(1.140)\end{array}$ & $\begin{array}{l}3.557^{* * *} \\
(1.132)\end{array}$ & $\begin{array}{l}4.139^{* * *} \\
(1.273)\end{array}$ & $\begin{array}{l}4.722^{* * *} \\
(1.066)\end{array}$ \\
\hline $\begin{array}{l}\text { Observations } \\
\text { Adj. R-Squared }\end{array}$ & $\begin{array}{c}471 \\
0.028\end{array}$ & $\begin{array}{c}471 \\
0.036\end{array}$ & $\begin{array}{c}472 \\
0.031\end{array}$ & $\begin{array}{c}471 \\
0.028\end{array}$ & $\begin{array}{c}474 \\
0.029\end{array}$ \\
\hline
\end{tabular}

Indep. Variables: Perceived Corruption $(0=$ no; $1=$ yes $)$, Male $(0=$ female; $1=$ male), Age(years), Mar$\operatorname{ried}(0=$ no; 1=yes), Education(years), Consumption per Cap.(annually, in log US-Dollar), Asset Value(total value of all hh assets), Asset Indices(derived via pca), Risk Taking, MPL(switching row from lottery to safe value, from 1 to 21), Confidence(in agricultural decisions from 1-always confident to 5-never confident), Trust in Outsiders(1-trust them not at all to 5-trust them a lot), Attendants(no. of attendants), Attendants Dummy $(0=$ no attendants; $1=$ attendants $)$. S.E. in parentheses.

${ }^{*} \mathrm{p}<0.10,{ }^{* *} \mathrm{p}<0.05,{ }^{* * *} \mathrm{p}<0.01$ 
Table 4: Robustness - Sample Weights, Interval, Ordered Logit and OLS Regressions

\begin{tabular}{|c|c|c|c|c|}
\hline & Sample Weights & Interval & O. Logit & OLS \\
\hline \multirow[t]{2}{*}{ Perceived Corruption } & $0.258^{*}$ & $14.325^{*}$ & $0.323^{*}$ & 0.226 \\
\hline & $(0.143)$ & $(8.418)$ & $(0.190)$ & $(0.139)$ \\
\hline \multirow[t]{2}{*}{ Male } & 0.054 & -0.639 & -0.010 & 0.015 \\
\hline & $(0.143)$ & $(8.347)$ & $(0.188)$ & $(0.137)$ \\
\hline \multirow[t]{2}{*}{ Age } & -0.057 & $-3.804^{*}$ & $-0.088^{*}$ & -0.053 \\
\hline & $(0.035)$ & $(2.012)$ & $(0.046)$ & $(0.032)$ \\
\hline \multirow[t]{2}{*}{$\mathrm{Age}^{2}$} & $0.001^{*}$ & $0.036^{* *}$ & $0.001^{* *}$ & $0.000^{*}$ \\
\hline & $(0.000)$ & $(0.018)$ & $(0.000)$ & $(0.000)$ \\
\hline \multirow[t]{2}{*}{ Married } & -0.100 & -2.290 & -0.027 & -0.034 \\
\hline & $(0.159)$ & $(9.247)$ & $(0.207)$ & $(0.151)$ \\
\hline \multirow[t]{2}{*}{ Education } & 0.001 & -0.747 & -0.017 & -0.010 \\
\hline & $(0.025)$ & $(1.411)$ & $(0.031)$ & $(0.023)$ \\
\hline \multirow[t]{2}{*}{ Consumption per Cap. } & 0.035 & 3.320 & 0.086 & 0.044 \\
\hline & $(0.115)$ & $(6.685)$ & $(0.150)$ & $(0.110)$ \\
\hline \multirow[t]{2}{*}{ Risk Taking, MPL } & 0.008 & -0.105 & -0.004 & 0.000 \\
\hline & $(0.008)$ & $(0.495)$ & $(0.011)$ & $(0.008)$ \\
\hline \multirow[t]{2}{*}{ Confidence } & 0.064 & 3.617 & 0.086 & 0.066 \\
\hline & $(0.064)$ & $(3.718)$ & $(0.083)$ & $(0.061)$ \\
\hline \multirow[t]{2}{*}{ Trust in Outsiders } & -0.076 & 1.465 & 0.035 & -0.005 \\
\hline & $(0.087)$ & $(5.201)$ & $(0.119)$ & $(0.085)$ \\
\hline \multirow[t]{2}{*}{ Attendants } & $-0.067^{*}$ & -2.760 & -0.057 & -0.046 \\
\hline & $(0.039)$ & $(2.219)$ & $(0.050)$ & $(0.036)$ \\
\hline \multirow[t]{2}{*}{ Constant } & $3.997^{* * *}$ & $268.817^{* * *}$ & & $4.335^{* * *}$ \\
\hline & $(1.195)$ & $(69.586)$ & & (1.139) \\
\hline \multirow[t]{2}{*}{ lnsigma } & & $4.325^{* * *}$ & & \\
\hline & & $(0.043)$ & & \\
\hline \multirow[t]{2}{*}{ cut1 } & & & $-3.796^{* *}$ & \\
\hline & & & $(1.569)$ & \\
\hline \multirow[t]{2}{*}{ cut2 } & & & -2.372 & \\
\hline & & & $(1.564)$ & \\
\hline \multirow[t]{2}{*}{ cut3 } & & & -1.529 & \\
\hline & & & $(1.562)$ & \\
\hline \multirow[t]{2}{*}{ cut4 } & & & -0.496 & \\
\hline & & & $(1.560)$ & \\
\hline Observations & 471 & 471 & 471 & 471 \\
\hline
\end{tabular}

Indep. Variables: Perceived Corruption $(0=$ no; $1=$ yes $)$, Male $(0=$ female; $1=$ male), Age(years), Mar$\operatorname{ried}(0=$ no; 1=yes), Education(years), Consumption per Cap.(annually, in log US-Dollar), Asset Value(total value of all hh assets), Asset Indices(derived via pca), Risk Taking, MPL(switching row from lottery to safe value, from 1 to 21), Confidence(in agricultural decisions from 1-always confident to 5-never confident), Trust in Outsiders(1-trust them not at all to 5-trust them a lot), Attendants(no. of attendants $)$, Attendants Dummy $(0=$ no attendants; $1=$ attendants $)$. S.E. in parentheses.

$* \mathrm{p}<0.10,{ }^{* *} \mathrm{p}<0.05,{ }^{* * *} \mathrm{p}<0.01$ 
Table 5: Weighted Regression Estimates for Aggregated Cheating Variables

\begin{tabular}{|c|c|c|c|}
\hline & pay 45 & pay345 & pay 2345 \\
\hline \multirow[t]{2}{*}{ Perceived Corruption } & $0.082^{*}$ & $0.092^{*}$ & $0.113^{* *}$ \\
\hline & $(0.046)$ & $(0.051)$ & $(0.049)$ \\
\hline \multirow[t]{2}{*}{ Male } & 0.018 & 0.040 & 0.011 \\
\hline & $(0.047)$ & $(0.051)$ & $(0.049)$ \\
\hline \multirow[t]{2}{*}{ Age } & -0.017 & -0.016 & -0.021 \\
\hline & $(0.012)$ & $(0.014)$ & $(0.013)$ \\
\hline \multirow[t]{2}{*}{$\mathrm{Age}^{2}$} & 0.000 & 0.000 & $0.000^{* *}$ \\
\hline & $(0.000)$ & $(0.000)$ & $(0.000)$ \\
\hline \multirow[t]{2}{*}{ Married } & -0.009 & -0.081 & $-0.096^{*}$ \\
\hline & $(0.052)$ & $(0.058)$ & $(0.055)$ \\
\hline \multirow[t]{2}{*}{ Education } & -0.002 & 0.005 & 0.013 \\
\hline & $(0.008)$ & $(0.009)$ & $(0.009)$ \\
\hline \multirow[t]{2}{*}{ Consumption per Cap. } & -0.005 & 0.018 & 0.001 \\
\hline & $(0.038)$ & $(0.042)$ & $(0.040)$ \\
\hline \multirow[t]{2}{*}{ Risk Taking, MPL } & 0.001 & $0.008^{* *}$ & $0.006^{* *}$ \\
\hline & $(0.003)$ & $(0.003)$ & $(0.003)$ \\
\hline \multirow[t]{2}{*}{ Confidence } & 0.026 & 0.021 & -0.012 \\
\hline & $(0.021)$ & $(0.023)$ & $(0.022)$ \\
\hline \multirow[t]{2}{*}{ Trust in Outsiders } & -0.043 & -0.035 & $-0.059 * *$ \\
\hline & $(0.027)$ & $(0.030)$ & $(0.028)$ \\
\hline \multirow[t]{2}{*}{ Attendants } & $-0.025^{* *}$ & -0.022 & $-0.032^{* *}$ \\
\hline & $(0.013)$ & $(0.014)$ & $(0.014)$ \\
\hline \multirow[t]{2}{*}{ Constant } & $0.729 *$ & 0.594 & $1.066^{* *}$ \\
\hline & $(0.398)$ & $(0.440)$ & $(0.422)$ \\
\hline Observations & 471 & 471 & 471 \\
\hline Adj. R-Squared & 0.005 & 0.019 & 0.050 \\
\hline
\end{tabular}

Dependent variables: pay 45 equals 1 if 4 or 5 are reported as rolled number and 0 otherwise, pay345 and pay2345 are analogously defined.

Indep. Variables: Perceived Corruption $(0=$ no; $1=$ yes $)$, Male $(0=$ female; $1=$ male $)$, Age(years), Mar$\operatorname{ried}(0=$ no; 1=yes), Education(years), Consumption per Cap.(annually, in log US-Dollar), Asset Value(total value of all hh assets), Asset Indices(derived via pca), Risk Taking, MPL(switching row from lottery to safe value, from 1 to 21), Confidence(in agricultural decisions from 1-always confident to 5-never confident), Trust in Outsiders(1-trust them not at all to 5-trust them a lot), Attendants(no. of attendants $)$, Attendants Dummy $(0=$ no attendants; $1=$ attendants $)$. S.E. in parentheses.

${ }^{*} \mathrm{p}<0.10,{ }^{* *} \mathrm{p}<0.05,{ }^{* * *} \mathrm{p}<0.01$ 
Table 6: Sample Split by Attendants Dummy

\begin{tabular}{|c|c|c|c|c|c|c|}
\hline & Attendants & No Attendants & Attendants & No Attendants & Attendants & No Attendants \\
\hline \multirow[t]{2}{*}{ Perceived Corruption } & 0.077 & $0.530^{* *}$ & 0.033 & $0.400^{*}$ & 0.185 & $0.561^{* *}$ \\
\hline & $(0.192)$ & $(0.224)$ & $(0.190)$ & $(0.228)$ & $(0.185)$ & $(0.218)$ \\
\hline \multirow[t]{2}{*}{ Male } & 0.211 & -0.190 & 0.202 & -0.110 & & \\
\hline & $(0.196)$ & $(0.218)$ & $(0.193)$ & $(0.225)$ & & \\
\hline \multirow[t]{2}{*}{ Age } & -0.015 & $-0.215^{* * *}$ & -0.013 & $-0.206^{* * *}$ & -0.042 & $-0.235^{* * *}$ \\
\hline & $(0.049)$ & $(0.072)$ & $(0.047)$ & $(0.071)$ & $(0.043)$ & $(0.070)$ \\
\hline \multirow[t]{2}{*}{$\mathrm{Age}^{2}$} & 0.000 & $0.002^{* * *}$ & 0.000 & $0.002^{* * *}$ & 0.000 & $0.002^{* * *}$ \\
\hline & $(0.000)$ & $(0.001)$ & $(0.000)$ & $(0.001)$ & $(0.000)$ & $(0.001)$ \\
\hline \multirow[t]{2}{*}{ Married } & -0.250 & -0.348 & -0.256 & -0.302 & & \\
\hline & $(0.230)$ & $(0.238)$ & $(0.223)$ & $(0.252)$ & & \\
\hline \multirow[t]{2}{*}{ Education } & 0.040 & -0.028 & $0.058^{*}$ & -0.016 & & \\
\hline & $(0.034)$ & $(0.039)$ & $(0.034)$ & $(0.037)$ & & \\
\hline \multirow[t]{2}{*}{ Consumption per Cap. } & -0.086 & 0.128 & & & & \\
\hline & $(0.164)$ & $(0.173)$ & & & & \\
\hline \multirow[t]{2}{*}{ Risk Taking, MPL } & $0.026^{* *}$ & -0.011 & $0.028^{* *}$ & -0.014 & & \\
\hline & $(0.011)$ & $(0.014)$ & $(0.011)$ & $(0.013)$ & & \\
\hline \multirow[t]{2}{*}{ Confidence } & -0.015 & 0.176 & -0.012 & $0.207^{*}$ & & \\
\hline & $(0.084)$ & $(0.110)$ & $(0.083)$ & $(0.110)$ & & \\
\hline \multirow[t]{2}{*}{ Trust in Outsiders } & $-0.177^{*}$ & 0.110 & -0.162 & 0.065 & & \\
\hline & $(0.107)$ & $(0.140)$ & $(0.106)$ & $(0.137)$ & & \\
\hline \multirow[t]{2}{*}{ Asset Value } & & & $-0.149^{* *}$ & 0.012 & & \\
\hline & & & $(0.061)$ & $(0.083)$ & & \\
\hline \multirow[t]{2}{*}{ Constant } & $2.916^{*}$ & $7.536^{* * *}$ & $3.449^{* *}$ & $8.149^{* * *}$ & $3.079^{* * *}$ & $8.741^{* * *}$ \\
\hline & $(1.544)$ & $(2.414)$ & $(1.375)$ & $(2.143)$ & $(1.130)$ & $(1.948)$ \\
\hline Observations & 299 & 172 & 299 & 172 & 302 & 173 \\
\hline Adj. R-Squared & 0.024 & 0.100 & 0.042 & 0.076 & 0.000 & 0.095 \\
\hline
\end{tabular}

Indep. Variables: Perceived Corruption $(0=$ no; $1=$ yes $)$, Male $(0=$ female; $1=$ male), Age(years $)$, Married $(0=$ no; $1=$ yes $)$, Education(years), Consumption per Cap.(annually, in log US-Dollar), Asset Value(total value of all hh assets), Asset Indices(derived via pca), Risk Taking, MPL(switching row from lottery to safe value, from 1 to 21), Confidence(in agricultural decisions from 1-always confident to 5-never confident), Trust in Outsiders(1-trust them not at all to 5-trust them a lot), Attendants(no. of attendants), Attendants Dummy( $0=$ no attendants; $1=$ attendants $)$. S.E. in parentheses. $* \mathrm{p}<0.10, * * \mathrm{p}<0.05, * * * \mathrm{p}<0.01$ 


\section{Appendix}

\section{A Instructions}

1 Which number is rolled by the die? (Please show the payoff table to the respondent and pass him the box and the six-sided die. Ask him to secretly roll the die several times and to keep the first number he rolled in mind.)

\begin{tabular}{|l|l|}
\hline Number rolled & Payoff \\
\hline 1 & 50 \\
\hline 2 & 100 \\
\hline 3 & 150 \\
\hline 4 & 200 \\
\hline 5 & 250 \\
\hline 6 & 0 \\
\hline
\end{tabular}

2 What is the first number rolled? Rolled number

3 How many persons are currently around and watching the scenario? (Do not count the respondent and the enumerator)

\section{B Construction of the Asset Factors}

Among others, assets are considered as covariate of cheating. They are measured in two ways: First, assets are measured by the logarithm of the value of total assets. Second, we bundle assets via a principal component analysis (PCA). There, we find two components: household assets and agricultural assets. The results of the two-factor PCA after varimax rotation are presented below. The scores based on the components are defined as two independent asset covariates of cheating. We use scoring coefficients of assets larger than 0.25 for the interpretation of the two principal components. For the first principal these are pickup, computer, gas stove, vacuum cleaner, and washing machine. For the second we find knapsack sprayer, water pump, pigsty, fishing net, and other farm assets. Therefore, we interpret the first component as the household assets factor and the second as the agricultural assets factor. 


\section{Individual Attitudes and Characteristics}

Figure C.1: Distribution of Switching Rows in MPL for Risk Taking

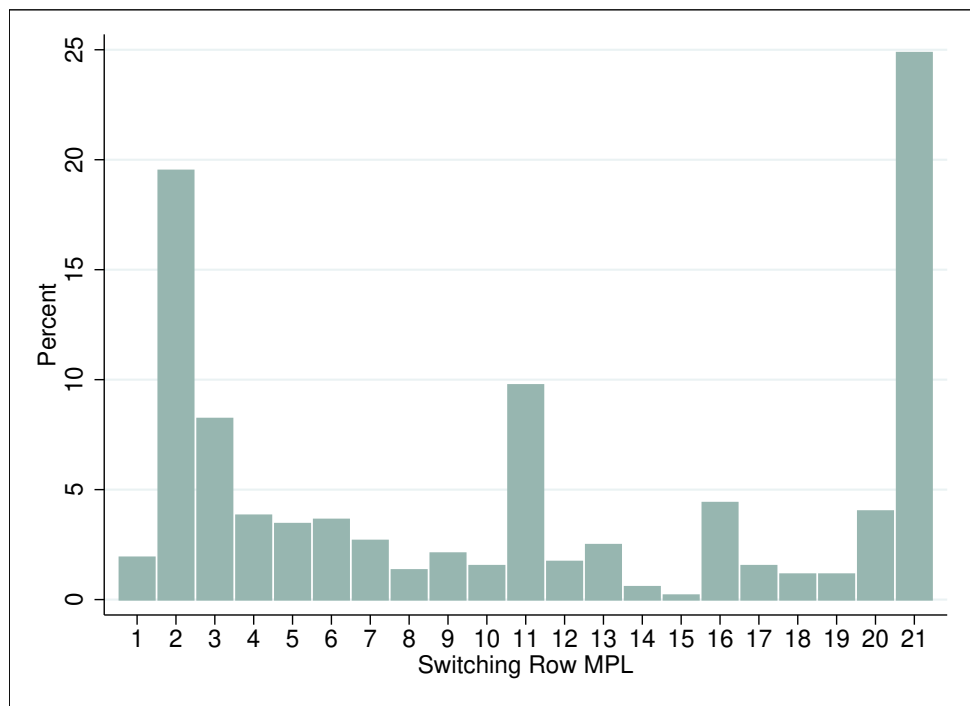

Figure C.2: Distribution of Confidence in Agricultural Decisions

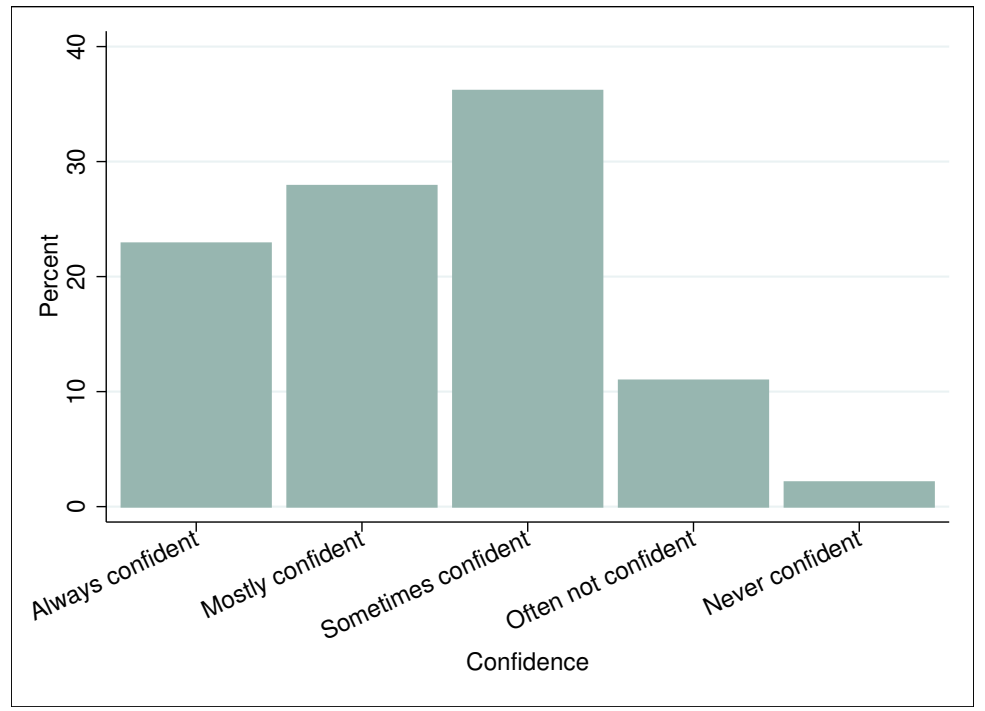


Figure C.3: Distribution of Trust in Outsiders

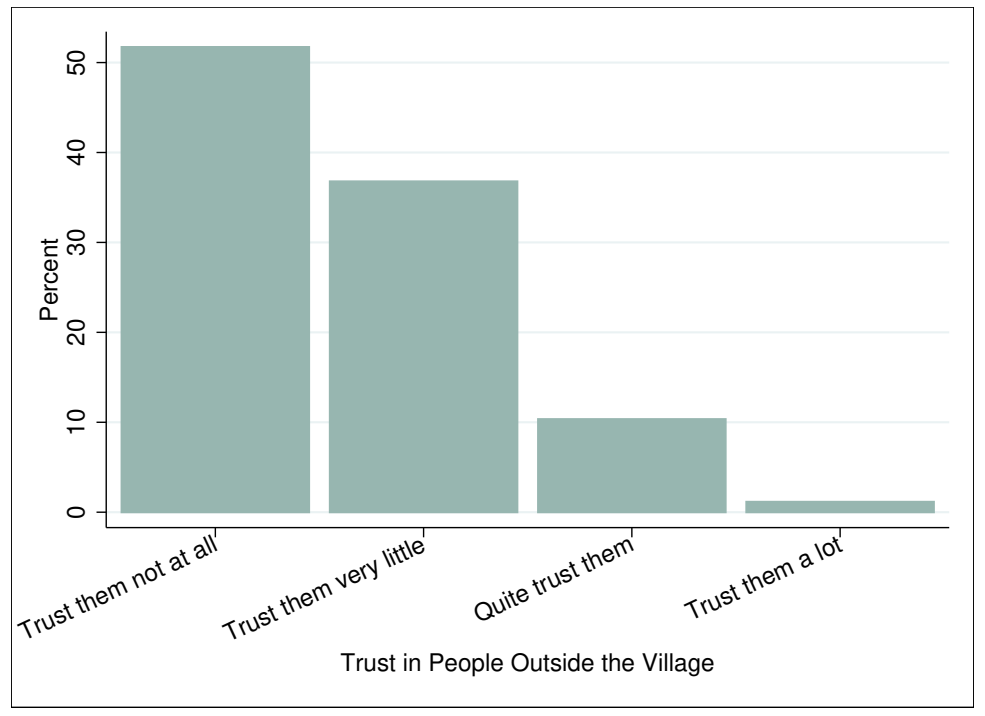

\section{Implementation of the Weighted OLS Approach}

Weighting schemes should be based on the basic population but this information is not available. Therefore, conducted estimates are weighted by the observed frequencies in each category under the maximum available sample size. Furthermore, the weights are standardized by the share of persons who reported to have rolled a 6 . The observed frequency distribution implies that the weighting is based on the full sample of participating individuals, i.e. 860 persons, while our benchmark regression (in Table 3, column 1) is based on 510 observations. There are two reasons to use the large sample: first, the largest possible sample provides the best information approximating the true full sample. Second, if we use a reduced sample, weights had to be calculated several times due to the different sample sizes, which would induce an element of variation that makes the results less comparable.

We recode the stated numbers into an ordered variable with respect to the outcome (Table D.2). The purpose is to receive a uniformly ordered variable. The weights are then determined in four steps.

- Step 1: We calculate the number of observations under the assumption of a uniform distribution, this means in our sample $860 / 6=143(.333)$.

- Step 2: We calculate the difference between the actual number of observations and the number of observations under step 1: 0: 59-143=-84; 1: 76-143=-67; 2: 138-143=-5; 3: 149-143=6; 4: 188-143=45; 5: 250-143=107. This actual number of observations minus the theoretical number under a uniform distribution is a hint of the degree of cheating. The greater the difference the higher is the probability that the respondent lies.

- Step 3: We determine the difference between the results of step 2 minus the result of step 2 for 0 . This means: $0:-84+84=0 ; 1:-67+84=17 ; 2:-5+84=79 ; 3: 6+84=90 ; 4: 45+84=129 ; 5$ : $107+84=191)$.

- Step 4: The reciprocal values of step 3 are the elements of a grouping matrix (Johnston 1972, p. 228): 

1: $1 / 17=0.0588235$
2: $1 / 79=0.0126582$
3: $1 / 90=0.0111111$
4: $1 / 129=0.0077519$
5: $1 / 191=0.0052356$

The expression for 0 is indeterminate $(1 / 0)$. Therefore, we assume a small number different from zero, namely $1 / 10000$.

Using these weights, estimates of a standard model of cheating are presented in Table 3. We use this weighting scheme for all estimates. The empirical distribution of payoff does not differ significantly under the sample sizes of 523 and 337 (860-523), the null hypothesis of uniform distribution cannot be rejected (Kolmogorov-Smirnov, two-sided $\mathrm{p}=0.995$ ).

Table D.1: Frequency Distribution of Rolled Number

\begin{tabular}{cccc}
\hline Dice & Frequency & Percent & Cumulative \\
\hline 1 & 76 & 8.84 & 8.84 \\
2 & 138 & 16.05 & 24.88 \\
3 & 149 & 17.33 & 42.21 \\
4 & 188 & 21.86 & 64.07 \\
5 & 250 & 29.07 & 93.14 \\
6 & 59 & 6.86 & 100.00 \\
\hline Total & 860 & 100.00 & \\
\hline
\end{tabular}

Table D.2: Recoded Frequency Distribution

\begin{tabular}{cccc}
\hline Pay & Frequency & Percent & Cumulative \\
\hline 0 & 59 & 6.86 & 100.00 \\
1 & 76 & 8.84 & 8.84 \\
2 & 138 & 16.05 & 24.88 \\
3 & 149 & 17.33 & 42.21 \\
4 & 188 & 21.86 & 64.07 \\
5 & 250 & 29.07 & 93.14 \\
\hline Total & 860 & 100.00 & \\
\hline
\end{tabular}




\section{E Additional Figures}

Table E.1: Descriptive Statistics by the Presence of Attendants

\begin{tabular}{lccc}
\hline & Attendants & No Attendants & Difference \\
\hline Male & 0.34 & 0.35 & 0.01 \\
Age & 55.34 & 55.06 & -0.28 \\
Married & 0.78 & 0.73 & -0.05 \\
Education & 5.26 & 5.69 & 0.43 \\
Consumption per Cap. & 7.09 & 7.09 & -0.00 \\
Asset Value & 8.35 & 8.58 & $0.23^{*}$ \\
Asset Index, 1. Factor & -0.14 & 0.05 & 0.19 \\
Asset Index, 2. Factor & -0.05 & -0.01 & 0.03 \\
Risk Taking, MPL & 11.24 & 10.44 & -0.79 \\
Confidence & 2.48 & 2.32 & $-0.16^{*}$ \\
Trust in Outsiders & 1.62 & 1.58 & -0.04 \\
Perceived Corruption & 0.74 & 0.75 & 0.01 \\
\hline Observations & 328 & 185 & 513 \\
\hline
\end{tabular}

Variables: $\operatorname{Male}(0=$ female; $1=$ male), Age(years), Married $(0=$ no; $1=$ yes), Education(years), Consumption per Cap.(annually, in log US-Dollar), Asset Value(total value of all hh assets), Asset Indices(derived via pca), Risk Taking, MPL(switching row from lottery to safe value, from 1 to 21), Confidence(in agricultural decisions from 1-always confident to 5 -never confident), Trust in Outsiders(1-trust them not at all to 5 -trust them a lot), Attendants(no. of attendants), Attendants Dummy ( $0=$ no attendants; $1=$ attendants $)$, Perceived Corruption $(0=$ no; $1=$ yes $)$.

${ }^{*} \mathrm{p}<0.10,{ }^{* *} \mathrm{p}<0.05,{ }^{* * *} \mathrm{p}<0.01$ 